\title{
Use of passive-microwave data to monitor spatial and temporal variations of snow cover at tree line near Churchill, Manitoba, Canada
}

\author{
Frédérique C. Pivot, ${ }^{1}$ Glaude Kergomard, ${ }^{2}$ Claude R. Duguay ${ }^{1}$ \\ ${ }^{1}$ LTMEF, Centre d'Études Nordiques et Département de Géographie, Université Laval, Sainte-Foy, Québec G1K 7P4, Canada \\ ${ }^{2}$ CNRS FRE 2170, Géographie des Milieux Anthropisés, Université des Sciences et Technologies de Lille, \\ Villeneuve d'Ascq, 59655 Lille Cedex, France
}

\begin{abstract}
We evaluated the contribution of Special Sensor Microwave/Imager (SSM/I) passive-microwave data to the monitoring of spatial and temporal variability of snow cover in the Churchill area, Manitoba, Canada. Because of the coarse spatial resolution of current passive-microwave sensors, the estimation of snow water equivalent using empirical equations with these instruments is largely compromised in complex areas such as Churchill (forest-tundra ecotone). However, with its high frequency of observations and the availability of a long time series (1988-99), passive-microwave data from the SSM/I radiometer remain a very valuable tool for monitoring the temporal evolution of snow cover at various spatial scales. Through winter 1997/98, we first examined the passive-microwave signatures at the local scale and we identified the major stages of the snow period. Principal-component analysis (PCA) applied on spectral-difference $\left(T_{\mathrm{b}}(19 \mathrm{H})-T_{\mathrm{b}}(37 \mathrm{H})\right)$ time series $(1988-99)$ enabled us to identify spatio-temporal effects over a large area. PCA also permitted the extraction of indices of relevance for monitoring climatic variability and climate change (annual snow-cover duration, dates of snow-cover appearance and disappearance).
\end{abstract}

\section{INTRODUCTION}

In this paper, we evaluate the potential of Special Sensor Microwave/Imager (SSM/I) passive-microwave data for monitoring the spatial and temporal variability of snow cover in the Churchill area, Manitoba, Canada. Churchill is located in the Hudson Bay Lowlands (Fig. 1), at $59^{\circ} \mathrm{N}$, at the transition between the High Subarctic and the Low Arctic ecoclimatic zones (Pivot, 2000). This zone is characterized by a strong climatic gradient where the boreal-forest-tundra ecotone prevails. As it is crossed right through by the northern limit of tree line, by the southernmost limit of continuous permafrost and by the aerological discontinuity of the Arctic Front, the Churchill area is indeed a very diverse geographical environment. Open spruce woodland is followed by forested and shrub tundra over a distance of barely $100 \mathrm{~km}$. The variety of vegetation and substrate types strongly influence the way in which snow cover at the surface is redistributed during the accumulation of fresh snow (annual solid precipitation is around $200 \mathrm{~mm}$ ), and then through the metamorphism of the snowpack. An examination of snow depths, water equivalents and densities measured in the field during winter 1997/98 showed great spatial variability in snow- cover conditions, in particular a clear difference between opened and closed sites. Also noteworthy is the intermediate and distinctive position of the transition zone where the deepest snow covers are encountered.

Boudreau and Rouse (1994) evaluated the potential of data acquired by the SSM/I radiometer to estimate snow physical parameters in the vicinity of Churchill. More

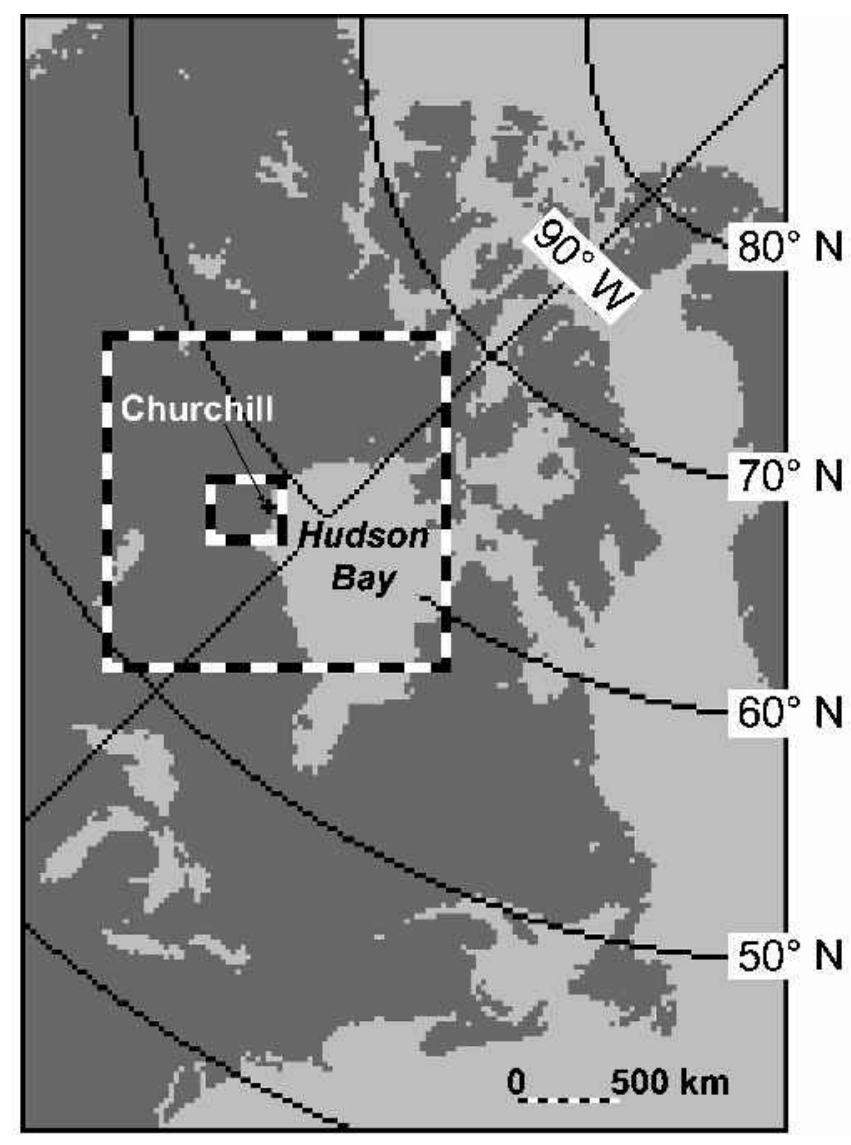

Fig. 1. Churchill study area, Manitoba, Canada. The small cross and two boxes represent the three scales at which the SSM/I data were analyzed. 
specifically, they tested the snow water-equivalent algorithm previously developed by Environment Canada in homogeneous areas of the Western Great Plains of Canada (Walker and Goodison, 1993). These authors confirmed the difficulty of determining snow-cover parameters using empirical models based on the spectral gradient method, in a physical environment as complex and heterogeneous as the Churchill area. Using a single $\mathrm{SSM} / \mathrm{I}$ gridcell extracted in this study area inevitably juxtaposes a very large variety of substrates, snow covers and vegetation types whose physical properties and roughness characteristics significantly affect the microwave emission.

Therefore, the main aim of the present study was not to attempt to improve or develop a regional algorithm which would allow estimation of the water content of the High Subarctic snow-covered areas using passive-microwave data, but rather to observe the way in which the difference between the brightness temperatures at 19 and $37 \mathrm{GHz}$ (spectral difference) in horizontal polarization remains sensitive to the variability in snow conditions, in both space and time. Indeed, because of the high frequency of observations and the availability of a long time series, the $\mathrm{SSM} / \mathrm{I}$ sensor is a particularly well-adapted tool for monitoring the temporal evolution of snow cover at regional to global scales (snow appearance and disappearance, snowmelt, snow duration), even if one considers the difficulties of estimating snow water equivalent in the Churchill area. Consequently, in this paper, we proceed with a detailed study at various spatial scales using SSM/I passive-microwave data acquired between 1988 and 1999 (Fig. 1). Firstly, spectral signatures for a single SSM/I gridcell centred on Churchill were examined. Because of the proximity of Churchill to the coast of Hudson Bay, we carefully chose the gridcell location so as to exclude the Hudson Bay seaice-cover effect in the SSM/I brightness temperatures. Using the land-cover map of Canada (Cihlar and Beaubien, 1998) produced from the U.S. National Oceanic and Atmospheric Administration (NOAA) Advanced Very High Resolution Radiometer (AVHRR) imagery, we identified the specific land-cover composition of the chosen SSM/I gridcell. Around $18.7 \%$ of the cell is covered by open areas (tundra, wetland, shrubland and burns), $28.3 \%$ by a transition treed shrubland and $49.4 \%$ by the evergreen needleleaf low-density forest. According to Lafleur and others (1997), lakes and ponds occupy $32 \%$ of the surface area inside the open land, $24 \%$ in the transition zone and $17 \%$ in the open forest. Despite the presence of this complex mosaic of substrates and cover types with extremely different radiometric properties within a single SSM/I gridcell, spectral-differencebased algorithms allow local and seasonal variations in the behaviour of snow cover to be effectively monitored. Secondly, principal-component analysis (PCA) was used to examine the spatio-temporal variations of snow cover for a SSM/I time series of 11 years over a large area. The advantages of PCA applied to snow climatology and remote sensing have been demonstrated by Hughes and Robinson (1993), Brown and Goodison (1996), Frei and others (1996), Brown and Braaten (1997) and Derksen and others (2000). They performed PCA on the meteorological data recorded in situ during the 20th century as well as on the snow-cover parameters inferred from visible-band or passive-microwave imagery. In the present study, PCA is directly applied on the spectral-difference algorithm considered as a proxy of snow-cover conditions.

\section{THE PASSIVE-MIGROWAVE SIGNATURE OF SNOW GOVER}

\section{Data description and spectral-difference method}

Passive-microwave data from the multispectral radiometer $\mathrm{SSM} / \mathrm{I}$, projected on a polar stereographic grid and corresponding to the daily mean brightness temperatures recorded at the time of the U.S. Defense Meteorological Satellite Program (DMSP) satellite repeated overpasses (DMSP SSM/I brightness-temperature grids), were obtained from the U.S. National Snow and Ice Data Center (NSIDG). Two dual-frequency algorithms derived from the spectral-gradient method of Künzi and others (1982) and based on the difference between brightness temperatures measured at 19 and $37 \mathrm{GHz}$ in horizontal polarization were developed and applied to the data. Although research groups in Finland (Hallikainen and Jolma, 1992) and in Canada (Goodison and Walker, 1993) have demonstrated the superiority of the vertical polarization for retrieving snow-cover parameters, the horizontal polarization was chosen because it has shown greater sensitivity to surface conditions (Chang and others, 1991) and it is theoretically better able to detect thickness variations of snow covers that have undergone several metamorphic transformations (Hall and others, 1984), such as frequently occur in Churchill. The presence or absence of snow on the ground can be identified by averaging, on a 5 day basis (pentads), the spectral difference between brightness temperatures measured at $19 \mathrm{H}$ and $37 \mathrm{HGHz}$. In homogeneous areas, such as the Canadian Great Plains and the Russian Steppes, it has successfully been demonstrated that this algorithm usually represents a valuable snow water-equivalent index when snow cover is dry (Walker and Goodison, 1993). In addition, snowmelt occurrences (presence of liquid water within the snowpack) can efficiently be detected through the difference between maximum and minimum spectral differences recorded over a pentad. Beside the identification of the melt and refreeze cycles, the use of pentads additionally allows a decrease of the volume of data when long time series are analyzed.

At the same time, we also carefully inspected the pentads in order to ensure that working with these would not lead to any significant information loss, especially in relation to brief but significant events affecting the seasonal evolution of snow cover. Because they correspond to brightness temperatures acquired twice daily (ascending and descending overpasses) over our study area, SSM/I data provided by NSIDC in the Equal-Area SSM/I Earth Grid (EASE-Grid) format permit examination of the seasonal behaviour of snow cover at a fine temporal resolution. This provides a means of improving our understanding of the interactions between the passive-microwave signal and snow-cover conditions. Specific information on the EASE-Grid data product can be found in Armstrong and Brodzik (1995).

\section{Seasonal brightness temperatures at $19 \mathrm{H}$ and $37 \mathrm{HGHz}$ and fluctuations in spectral differences for a single SSM/I gridcell: an example from winter 1997/98}

The ability of SSM/I data to identify various stages during the snow-cover period (accumulation, date of appearance and disappearance of snow on the ground, snowmelt period) can be evaluated by comparing the spectral differences between $19 \mathrm{H}$ and $37 \mathrm{HGHz}$ computed for the winter 1997/98 
pentads and daily brightness temperatures for a single SSM/I gridcell, together with meteorological data (air temperature and precipitation) recorded at Churchill airport.

During the first part of winter (STAGE-I), the brightness temperatures at $37 \mathrm{H} \mathrm{GHz}$ in ascending and descending overpasses decrease jointly with the amount of snow on the ground because of the higher microwave diffusion by the

a)

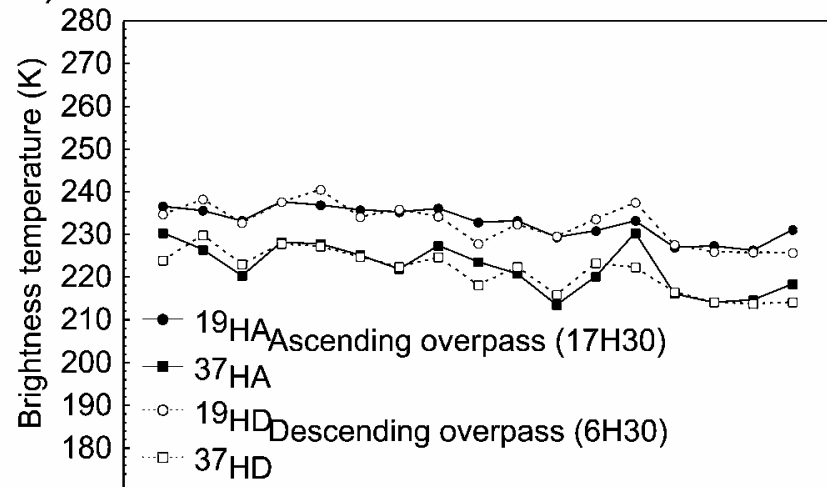

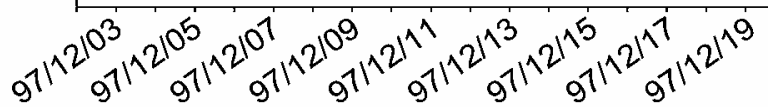

b)

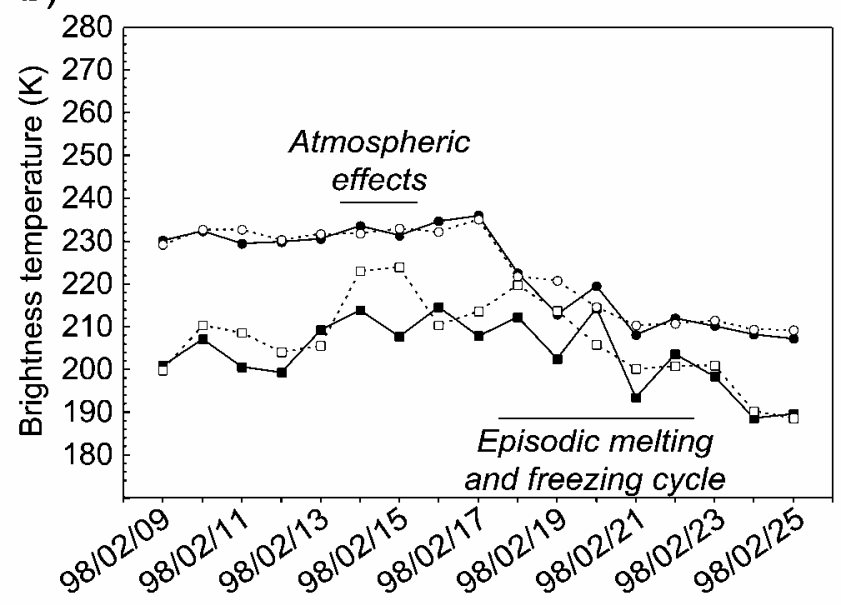

c)

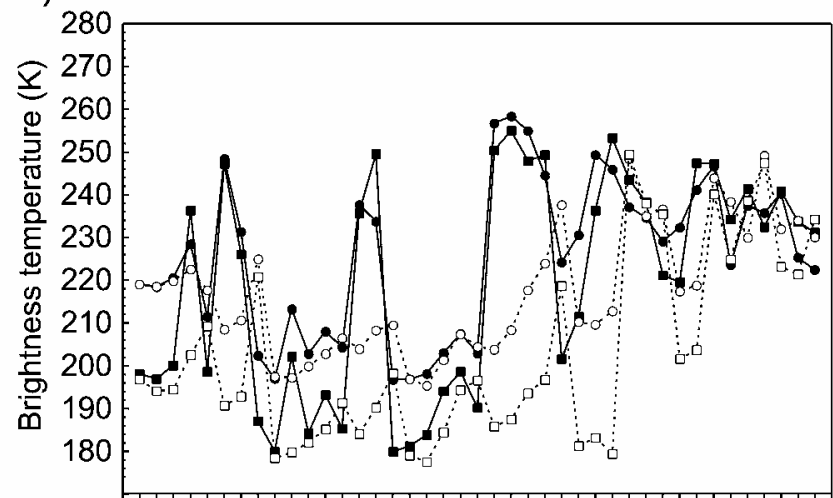

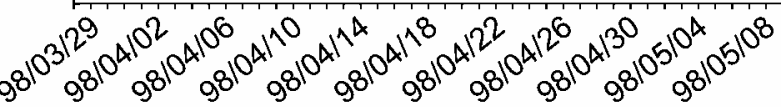

Fig. 2. Spectral signatures of snow cover for one SSM/I EASE-Grid cell centred on the Churchill area (winter 1997/ 98) at 19 and $37 \mathrm{GHz}$, in horizontal polarization, ascending and descending overpasses, during $(a)$ the snow-accumulation period, (b) an episodic snowmelt event and $(c)$ the snowmelt period before the disappearance of snow cover. Dates are yy/ $\mathrm{mm} / \mathrm{d}$. numerous snow particles (Fig. 2a). As the brightness temperatures at $19 \mathrm{H} \mathrm{GHz}$ remain quite stable (Fig. 2a), the mean spectral difference increases gradually and concurrently with snow accumulation (Fig. 3). For dry-snow conditions, emissivities decrease with increasing frequency (Mätzler, 1987). As long as air temperatures remain below approximately $0^{\circ} \mathrm{C}$, the snow cover is dry and the difference between the maximum and minimum spectral differences remains low.

On occasion, snowmelt events can occur in the middle of the winter season (STAGE-II). On 18 February 1998, for example, the diurnal air temperature rose above $0^{\circ} \mathrm{C}$ (Fig. 3 ), and the surface temperature recorded from a tower located in the open forest in the vicinity of Churchill reached $3.75^{\circ} \mathrm{C}$ during the descending overpass. The presence of wet snow, confirmed by field observations on that day, strongly affects the microwave signal so that the brightness temperature measured at $37 \mathrm{H} \mathrm{GHz}$ increases by $5 \mathrm{~K}$ (Fig. 2b). The microwave signature of wet snow is similar to that of a snow-free surface and opposite to that of a dry snow cover; emissivities increase with increasing frequency (Mätzler, 1987). Therefore, the difference between $19 \mathrm{H}$ and $37 \mathrm{HGHz}$ frequencies tends to be considerably smaller. On 19 February 1998, due to a return to more severe climatic conditions, the liquid
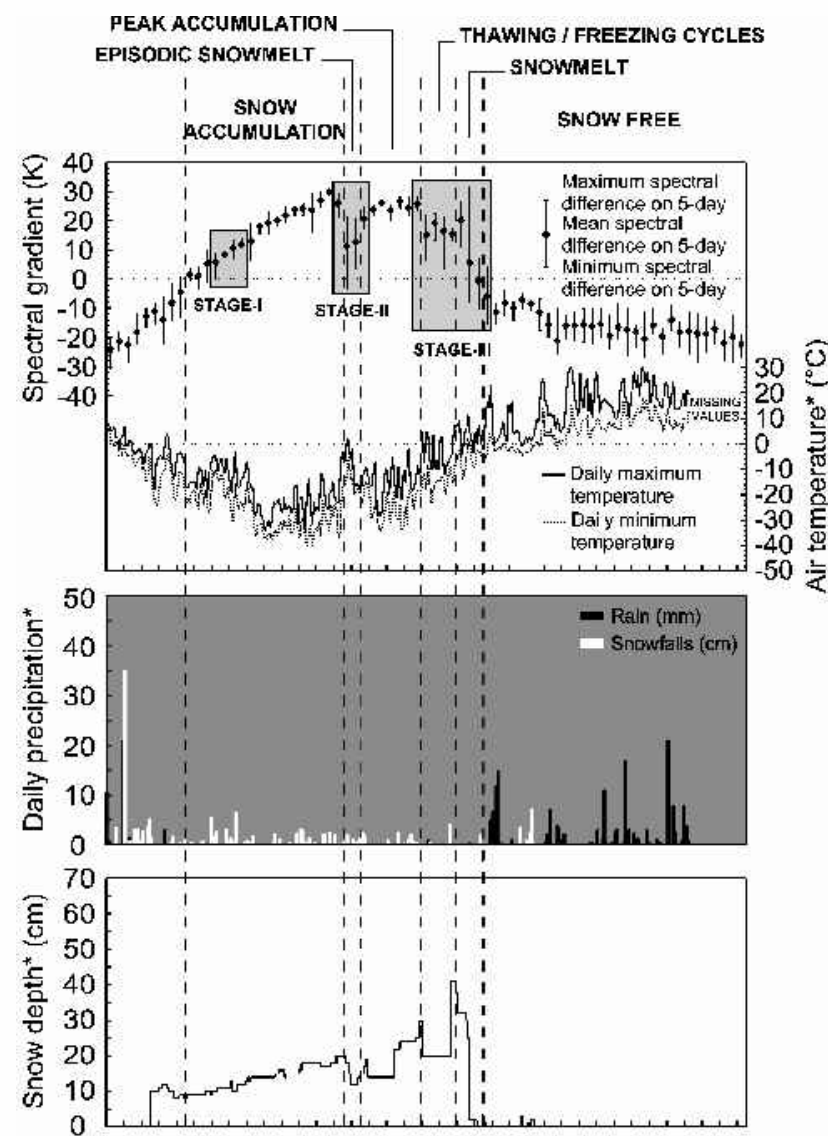

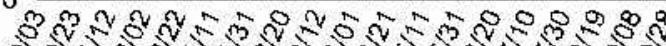

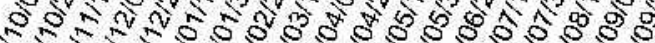

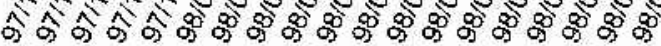

*Source : Churchill Airport meteorological data $(5060600)$ - Atmospheric Environment Service: Environment Canada

Fig. 3. Temporal fluctuations of the maximum, mean and minimum differences between the brightness temperatures at $19 \mathrm{H}$ and $37 \mathrm{H} \mathrm{GHz}$ for one SSM/I gridcell centred on the Churchill area vs the meteorological data (air temperature, precipitation and snow on the ground) recorded at Churchill airport during winter 1997/98. Dates are yy/mm/dd. 
water contained in the snow cover refroze, inducing a great increase in the spectral difference. Finally, even on a 5 day basis, one can observe a substantial decrease of the mean spectral difference which corresponds to a drop in snow depths and an important lag between the maximum and minimum spectral differences, testifying to the presence of the brief snowmelt and refreezing events (Fig. 3). However, the decrease in brightness temperatures between 9 and 25 February 1998 (Fig. 2b) can be attributed to the $10 \mathrm{~cm}$ increase of the depth-hoar layer thickness at the bottom of the snow cover, as observed and measured at several places in the field (Pivot, 2000). Depth hoar consists of sizeable snow particles $(\phi>4 \mathrm{~mm})$ with a high microwave scattering power, which is typically responsible for a decrease in snowcover emissivity and thus brightness temperature. Beside the depth-hoar effect, a decrease in the polarization difference by about 20 and $9.5 \mathrm{~K}$ at 19 and $37 \mathrm{GHz}$ frequencies, respectively, has been computed from the available EASE-Grid data between the two dates. According to Surdyk and Fily (1995), this is related to significant stratigraphic changes within the snow cover. The metamorphism due to melting and refreezing simultaneously modifies the spectral signature of the snow cover by altering its internal structure (increase in the number of snow layers). A thorough examination of the EASE-Grid data throughout this period also allows the influence of atmospheric effects on passive microwaves to be observed (Fig. 2b). Indeed, on 14 and 15 February, the presence of a disturbance and snowy clouds over the Churchill area possibly generated a rise of brightness temperatures at 37HGHz. Atmospheric effects are usually stronger at higher frequencies. This is an important problem when snow studies are conducted using the $85 \mathrm{GHz}$ channel of SSM/I. However, Wang and others (1992) suggest that atmospheric absorption takes place even at $37 \mathrm{GHz}$, so that radiometric corrections remain essential for obtaining accurate estimates of snow water equivalent with satellite passive-microwave data.

At the beginning of April (STAGE-III), both $19 \mathrm{H}$ and $37 \mathrm{H} \mathrm{GHz}$ diurnal brightness temperatures (Fig. 2c) increase strongly because of the presence of liquid water in the snow cover. At night, during refreezing, the formation of crusts leads to an important increase of the spectral difference that significantly contrasts with the diurnal observations. These daily fluctuations are associated with variations in air temperature (Fig. 3) and in the thawing-freezing metamorphism process. Around 20 April, the snowpack probably reaches its isothermal condition, and the snowcover decay succeeds the melting-freezing cycles. This stage coincides with a sustained decrease of the spectral differences (Fig. 3). As soon as the differences become negative, the ground is free of snow.

\section{SYNTHESIS OF SNOW-COVER INFORMATION CON- TAINED IN THE SSM/I PASSIVE-MICROWAVE TIME SERIES USING PGA}

An archive of $>20$ years of snow-cover observations on a global scale is now available through the combination of the passive-microwave images from the Scanning Multichannel Microwave Radiometer (SMMR) and SSM/I. In contrast to images only recently acquired by synthetic aperture radar (SAR) sensors such as RADARSAT-1 (1995-present), passive-microwave data thus represent a significant source of information for studying climate varia- bility. However, the volume of such data to be processed is enormous. PCA, a well-known statistical technique for processing such voluminous time series, allows the information contained in extended multidimensional datasets to be efficiently reduced. PCA proceeds by a linear transformation of a series of numeric variables in order to create a new series of orthogonal factors (principal components (PGs)), which, unlike the input variables, are uncorrelated between them. The PGs are ordered in terms of the percentage of the explained variance contained in the original dataset (Eastman and Fulk, 1993). In this study, two PGAs were performed: a "spatial" PGA and a "temporal" PCA. All calculations were performed with the statistical software package SAS.

\section{The spatial approach: "normal" snow-season cycle and regional contrasts}

Earlier, we showed that the mean spectral differences for a single gridcell centred on Churchill could be regarded as a proxy of snow-cover conditions at the local scale. Thus, to regionalize our observations, we applied the mean spectraldifference method to a $65 \times 65$ window centred on the western section of the Hudson Bay Lowlands, extending roughly from the 60th Parallel to Lake Winnipeg (see Fig. 1). Here, the aim was to extract abnormal spatial features beyond the global character of the identified system (High Subarctic snow cover), in order to get a better idea of the spatial variability of snow cover. Finally, a non-standardized PCA with a Varimax rotation was performed, where the mean spectral differences were treated as the variables (784 pentads over the 11 year series of SSM/I observations) and the 4225 gridcells $(65 \times 65$ window $)$ were used as the observations. The first four PGs derived from this procedure summarize $92.2 \%$ of the information contained in the initial dataset.

$\mathrm{PCl}$ accounts for $44.3 \%$ of the explained variance. It describes the typical summer situation, mainly characterized by a very clear opposition between the ice-free Hudson Bay and the continent (Fig. 4a). Positive scores correspond to the summer pentads (higher loadings and low negative spectral differences) and are representative of the snow-free gridcells on land. Values fluctuate with the surface roughness induced by the various vegetation covers (boreal forest, subarctic transition zone and tundra). Negative scores are related to the winter pentads (high positive spectral differences) and are spatially attributed to the open-water gridcells on Hudson Bay. PC2 explains $36.1 \%$ of the variance and is symmetrical to PCl. In other words, it illustrates the typical winter situation where the land is snow-covered and Hudson Bay is frozen (Fig. 4b). The different ice-cover types are responsible for the disparities in factor scores on Hudson Bay. On land, the subarctic transition zone is clearly visible because of its specific spectral signature (the higher scores correspond to the lower emissivities at $37 \mathrm{HGHz}$ and higher spectral differences). Here, the amount of snow cover is higher than for the tundra. In contrast to the boreal forest, the snowcover-microwave interactions in the subarctic zone are not masked as much by the forest canopy.

PC3 and PC4 are also symmetrical. They summarize $7.2 \%$ and $4.6 \%$ of the explained variance, respectively. On PC3, the strongest loadings correspond to the snowmelt period. The higher scores are observed both in the arctic tundra and in the higher parts of the subarctic zone. They 
indicate snowmelt (Fig. 4c). Elsewhere, snow cover has disappeared. It is very interesting to note the particular position of Churchill, just between those two contrasting zones. Finally, the fourth component succeeds in time the third component. It shows ice decay on Hudson Bay in June, at which time the latitudes below $55^{\circ} \mathrm{N}$ are snow-free (Fig. 4d). The northern sea-ice drift is also clearly visible. The lower factor scores correspond to open-water areas, whereas the higher scores characterize the residual ice cover.

\section{The temporal approach: interannual variability of snow cover at tree line}

Here, the sea-ice gridcells were carefully removed and a standardized PCA with a Varimax rotation was performed on an $11 \times 13$ window centred on land, in the vicinity of Churchill (see Fig. 1). The first two components summarize $95.8 \%$ of the explained variance. PCl explains $54.3 \%$ of the variance and illustrates the seasonal behaviour of snow cover. This component shows: (1) in a general way, pentads characterized by snow on the ground (positive scores) against pentads free of snow (negative scores), and (2) in detail, pentads corresponding to the maximum snow amount on the ground (higher positive scores) against pentads corresponding to the date of snow disappearance (higher negative scores).

PC2, however, is probably the most interesting component ( $41.5 \%$ of the explained variance). It shows the interannual variability of snow-cover conditions and allows a rough estimate to be made of the snow-cover duration for each year within the period of observations. Observations corresponding to spectral differences above $0 \mathrm{~K}$ (pentads with snow on the ground) contribute primarily to the formation of the second axis (PC2). Thus, annual snow-cover duration can be
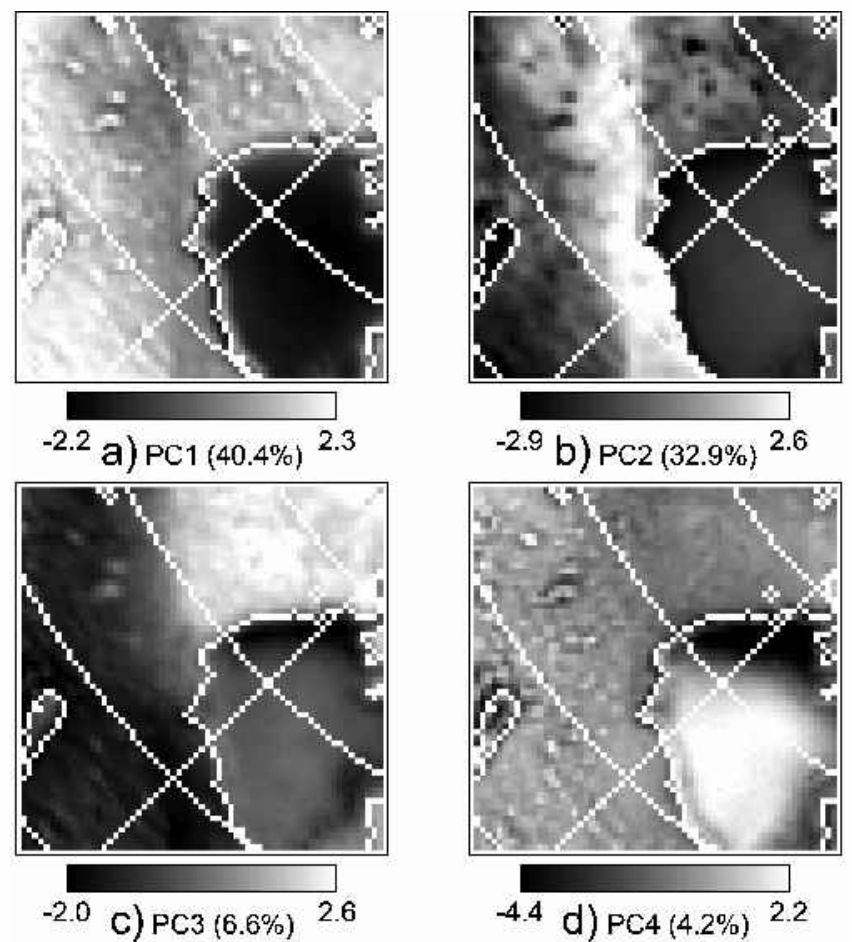

Fig. 4. Maps of PCA scores for the first four components of the "spatial" PCA. (a) PC1 and (b) PC2 represent typical summer and winter situations, respectively, whereas (c) PC3 and (d) PC4 correspond to snowmelt then ice decay on Hudson Bay. estimated through this component, since the reversal of the scores sign closely agrees with the dates of onset and disappearance of snow (Fig. 5a). In a further investigation, to be validated, this information will be compared with the meteorological data (e.g. daily snow-depth records) and the estimations issued from the weekly snow-extent maps for Northern Hemisphere land surfaces performed using visibleband U.S. National Oceanic and Atmospheric Administration (NOAA) Advanced Very High Resolution Radiometer (AVHRR) imagery. PC2 also depicts the interannual variability of snow cover, in a similar fashion to the mean spectral difference derived for the single SSM/I gridcell centred on Churchill (Fig. 5b). Indeed, the strength of the scores almost describes snow-depth fluctuations (Fig. 5c). Finally, two groups are opposed (Fig. 5a): (1) cold and/or snowy winters of 1988/89, 1991/92, 1993/94, 1994/95 and 1996/ 97 (positive scores) with mean spectral differences often greater than $30 \mathrm{~K}$; and (2) warm and/or dry winters of 1989/ 90, 1990/91, 1992/93, 1995/96, 1997/98, and 1998/99 (negative scores) with mean spectral differences not exceeding $30 \mathrm{~K}$.

Negative scores are also noticeable in the middle of

a)

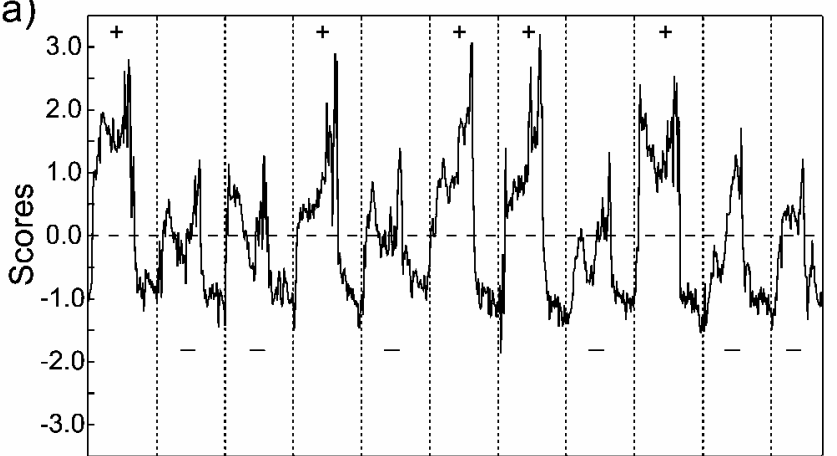

$88 / 10 / 05 \quad 90 / 10 / 05 \quad 92 / 10 / 05 \quad 94 / 10 / 05 \quad 96 / 10 / 05 \quad 98 / 10 / 05$ b) $89 / 10 / 05 \quad 91 / 10 / 05 \quad 93 / 10 / 05 \quad 95 / 10 / 05 \quad 97 / 10 / 05$
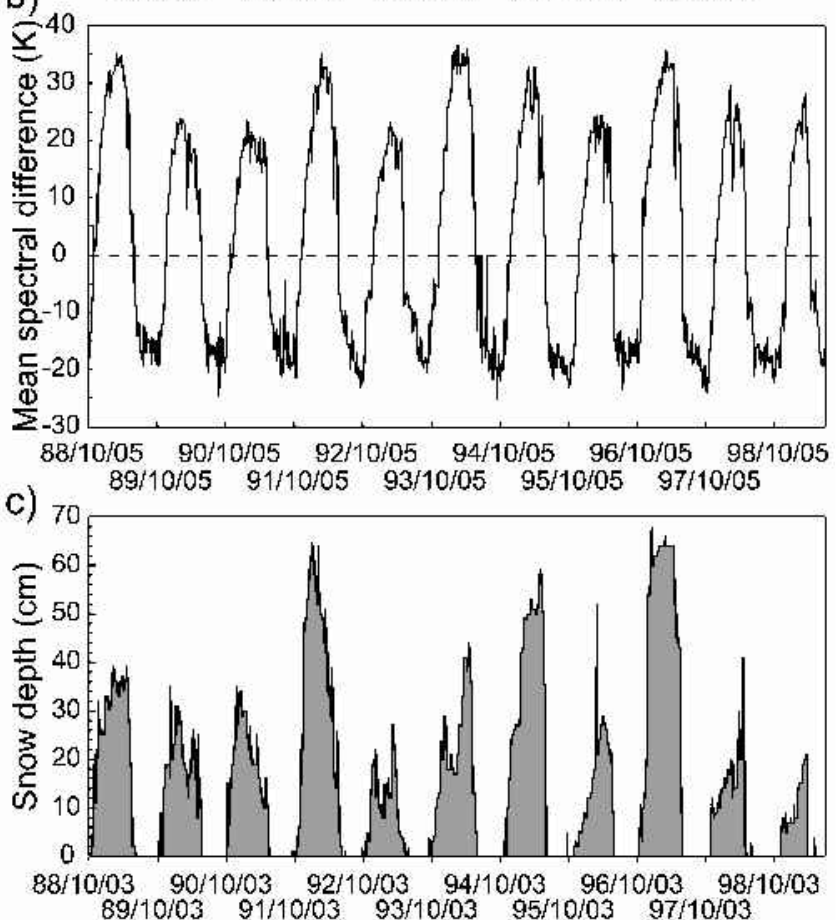

Fig. 5. "Temporal" PCA outputs related to the second component and some elements of interpretation. (a) PC2 scores; ( $b$ ) variations of the mean spectral difference recorded for one SSM/I gridcell around Churchill; (c) snow depth measured at Churchill airport. Dates are yy $/ \mathrm{mm} / \mathrm{dd}$. 

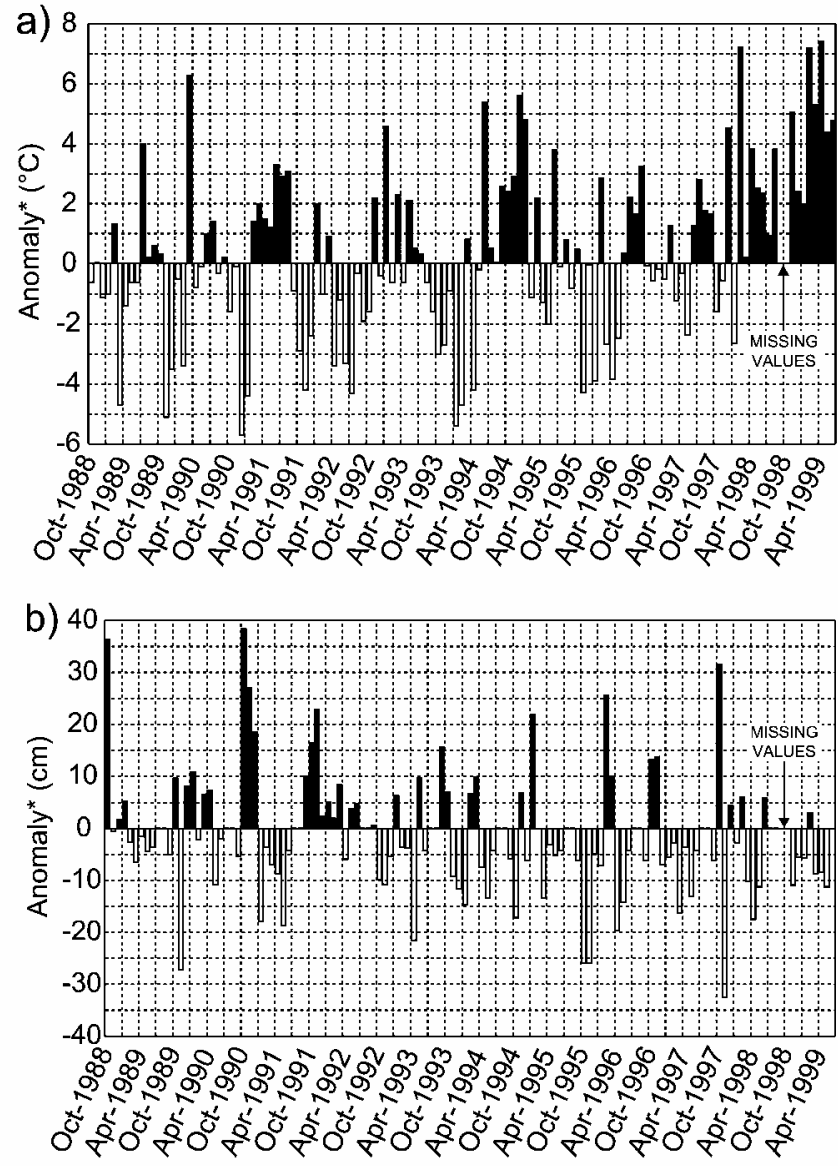

*Source : Churchill Airport meteorological data (5060600) - Atmospheric Environment Service, Environment Canada

Fig. 6. Climatic conditions, October 1988- June 1999, at Churchill airport. (a) and (b) correspond to the monthly air-temperature and precipitation anomalies with respect to a 1961-90 normal. Dates are yy $/ \mathrm{mm} / \mathrm{dd}$.

winter. They are associated with sudden changes affecting the spectral-difference values, sometimes due to an episodic snowmelt event (e.g. 1992/93) and sometimes due to a significant accumulation of snow on the ground following a winter storm (e.g. 1995/96). Monthly air-temperature and snowfall anomalies with respect to a 30 year normal from the weather station of Churchill airport are presented in Figure $6 \mathrm{a}$ and $\mathrm{b}$. Both graphs corroborate the interpretation of the second component by reproducing rather accurately the climatic conditions prevailing during winters 1988/89 to 1998/99. Except for the important amount of snowfall recorded in October, snow accumulation in 1988/89 was near normal. In March and April, however, the unusually low air temperatures largely contributed to the persistence of snow on the ground. Winters 1991/92 and 1996/97 were the snowiest of the 1990s. During those winters, a thick snow cover formed in the fall due to abundant snowfalls at the beginning of the snow-accumulation period as well as favourable temperatures. Interpreting winter 1994/95 with currently available information is more complicated. Most of the snow accumulated in November, and a snow cover $>50 \mathrm{~cm}$ thick was maintained over much of winter and a good part of spring. During the snow season, however, monthly air temperatures were $2.5-5.5^{\circ} \mathrm{C}$ higher than normal, except in February. In winter 1993/94, very low air temperatures appear to account for the spectral-differences rise above $30 \mathrm{~K}$, and consequently for the position of this winter on the second component.
Throughout winters 1992/93, 1995/96, 1997/98 and 1998/99, snowfall did not exceed $160 \mathrm{~cm}$ in total. These dry conditions explain the shallow snow depths and the lower scores for these winters compared to those described earlier. The lack of snowfall observed during winter $1997 / 98$ is undoubtedly caused by the occurrence of the temperature anomaly encountered in the Equatorial seas off South America, commonly known as El Niño. Indeed, the Southern Oscillation Index (SOI) fluctuations modify the atmospheric circulation (at the $5 \mathrm{~km}$ altitude) by splitting the jet stream over North America. Thus, in Canada, a severe snow deficit and an abnormal rise in temperature are typically ascertained during El Niño years (Brown and Goodison, 1996; Brown, 1998). This is obviously what happened during winters 1997/98 and 1998/99. Winter 1991/92 also witnessed an El Niño event, but did not produce the expected climate configuration. That particular year, higher dust concentrations in the stratosphere following the eruption of Mount Pinatubo, Philippines (June 1991), obscured the climatic effects of El Niño. According to Portman and Gutzler (1996), volcanic eruptions also play a significant role in interannual climate variability at global and regional scales.

Finally, a problem still remains. While the factor scores and the microwave signal are very similar in winters 1991/92 and 1993/94, snow-cover conditions were very different. We previously stated that in 1991/92 (Pinatubo year) the PCA outputs were explained mostly by abnormal snowfall, whereas in 1993/94 the main controlling factor was the abnormally cold temperatures. We know that the amount of snow vs the spectral-difference relationship is not unique. As the surface temperature also influences the brightness temperature, cold (warm) winters cannot be discriminated from snowy (dry) winters. Indeed, in the passive-microwave wavelengths, the brightness temperature measured for a given surface corresponds to the product of the emissivity of this surface and its physical temperature. Consequently, even if temperature only intervenes to the first power, compared to the thermal infrared wavelengths where it intervenes to the fourth power, its influence on the brightness temperature cannot be completely occulted. This problem will have to be taken into account in future improvements of passive-microwave snow algorithms.

\section{CONGLUSION}

Satellite data available from the passive-microwave radiometers are relatively well adapted and cover a sufficiently long time series to create a database on the spatio-temporal variability of snow-cover parameters such as snow extent, snow duration and dates of beginning and end of snowmelt. Thus, from a climate-variability/-change perspective, passive-microwave data will fulfil the current requirements of modern climatology with respect to snow-cover studies as soon as they appear sufficiently reliable for operational use (data assimilation or validation) by global climate models. In addition, the daily frequency observations and the long time series collected since the end of the 1970s (SMMR and SSM/I data) provide an unprecedented opportunity for monitoring the seasonal and the interannual variability of snow-cover parameters over large areas. With the gradual closing of manned weather stations at high latitudes over the last decade, satellite remote sensing presents the most promising means of monitoring snow-cover parameters of relevance to climate change in northern Canada. 
PGA is suitable for the extraction of spatial and temporal patterns on such remote-sensing image time series. By the frequency of its observations, SSM/I is mainly a tool for the analysis of the temporal evolution of snow cover. At the small scale, PCA allows well-known spatial features to be highlighted, especially in identifying distinctive snow-accumulation patterns at tree line and ice decay on Hudson Bay. Nevertheless, the coarse spatial resolution of the current passive-microwave radiometers is an impediment to the temporal monitoring of the mass balance of snow in the High Subarctic. The position of Churchill in a strong gradient area, where one promptly passes from open forest to tundra, was clearly highlighted; thus, it becomes more difficult to estimate snow water equivalent in this type of environment. In this particularly heterogeneous landscape, the complexity of the interactions between microwave radiation and the internal structure of snow cover, the variability of the microwave signal with the various cover types and, finally, the ambiguity related to the effect of atmospheric temperatures on brightness temperatures represent the primary limits to the development of efficient snow-cover algorithms based on empirical models.

\section{AGKNOWLEDGEMENTS}

Financial assistance for this research was provided by the Meteorological Service of Canada, in support of the GRYSYS program and the Natural Sciences and Engineering Research Council of Canada (C. Duguay). We thank the NSIDG Distributed Active Archive Center (DAAG), Boulder, CO, for providing the SSM/I data. We are grateful to A. T. C. Chang and an anonymous reviewer for providing valuable comments on an earlier version of the manuscript.

\section{REFERENGES}

Armstrong, R. L. and M. J. Brodzik. 1995. An earth-gridded SSM/I data set for cryospheric studies and global change monitoring. Adv. Space Res., 16(10), 155-163.

Boudreau, D. L. and W. R. Rouse. 1994. Algorithm testing of passive-microwave monitoring of snow water equivalent in a tundra environment. Downsview, Ont., Environment Canada. Atmospheric Environment Service. (Final report.)

Brown, R. D. and R. O. Braaten. 1997. Spatial and temporal variability of
Canadian monthly snow depths, 1946-1995. Proc. East. Snow Conf., 54th Annual Meeting, 4-9 May 1997, Banff, Alta, Canada, 37-45.

Brown, R. D. and B. E. Goodison. 1996. Interannual variability in reconstructed Canadian snow cover, 1915-1992. .7. Climate, 9(6), 1299-1318.

Chang, A. T. C., J. L. Foster and A. Rango. 1991. Utilization of surface cover composition to improve the microwave determination of snow water equivalent in a mountain basin. Int. F. Remote Sensing, 12(11), 2311-2319.

Cihlar, J. and J. Beaubien. 1998. Land cover of Canada. Version 1.1. Ottawa, Ont., Natural Resources Canada. Canada Centre for Remote Sensing and Canadian Forest Service. NBIOME Project. (Special Publication.)

Derksen, C., E. LeDrew and B. Goodison. 2000. Temporal and spatial variability of North American Prairie snow cover (1988 to 1995) inferred from passive microwave derived snow water equivalent (SWE) imagery. Water Res. Res., 36(1), 255-266.

Eastman, J. R. and M. Fulk. 1993. Long sequence time series evaluation using standardized principal components. Photogramm. Eng. Remote Sensing, 59(6), 991-996.

Frei, A., D. A. Robinson and M. G. Hughes. 1996. A regional analysis of North American snow cover extent: climatic and synoptic associations from November through March. Proc. East. Snow Conf., 53rd Annual Meeting, 1-3 May 1996, Williamsburg, Virginia, 33-42.

Goodison, B. E. and A. E. Walker. 1993. Use of snow cover derived from satellite passive-microwave data as an indicator of climate change. Ann. Glaciol., 17, 137-142.

Hall, D. K., J. L. Foster and A. T. C. Chang. 1984. Nimbus-7 SMMR polarization responses to snow depth in the mid-western U.S. Nord. Hydrol., 15(1), $1-8$.

Hallikainen, M.T. and P. A. Jolma. 1992. Comparison of algorithms for retrieval of snow water equivalent from Nimbus-7 SMMR data in Finland. IEEE Trans. Geosci. Remote Sensing, GE-30(1), 124-131.

Hughes, M. G. and D. A. Robinson. 1993. Snow cover variability in the Great Plains of the United States: 1910-1988. Proc. East. Snow Conf., 50th Annual Meeting, 8-10 June 1993. Québec, Que., Canada, 35-42.

Künzi, K. F., S. Patil and H. Rott. 1982. Snow-cover parameters retrieved from Nimbus-7 Scanning Multichannel Microwave Radiometer (SMMR) data. IEEE Trans. Geosci. Remote Sensing, GE-20(4), 452-467.

Lafleur, P. M., A. B. Wurtele and C. R. Duguay. 1997. Spatial and temporal variations in surface albedo of a subarctic landscape using surfacebased measurements and remote sensing. Arct. Alp. Res., 29(3), 261-269.

Mätzler, C. 1987. Applications of the interaction of microwaves with the natural snow cover. Remote Sensing Rev., 2, 259-387.

Pivot, F. C. 2000. Télédétection appliquée au suivi des variations spatio-temporelles du couvert nival à la limite des arbres (Churchill, Manitoba). (Ph.D. thesis, Université des Sciences et Technologies de Lille.)

Surdyk, S. and M. Fily. 1995. Results of a stratified snow emissivity model based on the wave approach: application to the Antarctic ice sheet. $\mathcal{F}$ Geophys. Res., 100(C5), 8837-8848.

Walker, A. E. and B. E. Goodison. 1993. Discrimination of a wet snowcover using passive-microwave satellite data. Ann. Glaciol., 17, 307-311.

Wang, J. R., A. T. C. Chang and A. K. Sharma. 1992. On the estimation of snow depth from microwave radiometric measurements. IEEE Trans. Geosci. Remote Sensing, GE-30(4), 785-792. 